\title{
REVIEWS
}

\section{MATHEMATICS APPLIED TO BIOLOGY}

MATHEMATICAL IDEAS IN BIOLOGY. J. Maynard Smith. Cambridge University Press, 1968. Pp. 152. 30s. (cloth), 12s. (paperback).

Professor Maynard Smith has written a valuable and original book about applications of mathematics to biological processes. It contains no statistics, not because of any doubts about the value of statistics but because there are already a number of good books on statistics intended for biologists. Its scope is very wide; it deals with the consequences of differences in size between animals, with the regulation of populations both when generations are separate and when they overlap, with applications of probability theory to genetics, with natural selection, with target theory (applied mainly to radiation biology), with control theory and with diffusion. It will be useful to undergraduates, lecturers and research workers in many branches of zoology and especially in ecology and genetics.

Professor Smith assumes little prior knowledge of mathematics in his readers, apart from the algebra that every scientist learns at school and the beginnings of calculus. He deliberately uses crude and clumsy mathematical methods which biology students are likely to understand in preference to more elegant ones which they are not, and he illustrates some theorems (including the binomial theorem of probability) instead of proving them. Nevertheless he assumes that his readers will have a certain amount of ability and the will to persevere, and does not always give them quite as much help and encouragement as he might. For instance he has left occasional steps in his algebra unexplained, and does not explain in words why (as the mathematics shows) a delay in a negative feedback loop gives rise to oscillations.

It is perhaps particularly necessary that a biologist plunged unwillingly into mathematics should be shown constantly that the mathematics is directly relevant to experimental results or observations of nature. The book could have been improved substantially by just a few more biological data. For instance, the discussion of the relationship between power output and body size in animals could have been illustrated by measured values of metabolic rate.

Each chapter ends with a few exercises, because " to learn mathematics requires practice just as much as learning to play the piano". Most of the exercises are rather difficult, but readers who persevere with them will find their understanding of the book greatly increased. Those who do not will miss some important points which are dealt with in the exercises but not in the main text. For instance, the rate of increase in a population of an advantageous dominant gene is dealt with in the text, but the case of an advantageous recessive is left to an exercise.

R. MaNeill Alexander

Department of Zoology, University of Leeds 